\title{
"Sustainable development in the context of climate change": a new approach for institutions of higher learning
}

\author{
Said Irandoust
}

Received: 26 June 2009/Accepted: 31 July 2009/Published online: 29 September 2009

(C) Integrated Research System for Sustainability Science, United Nations University, and Springer 2009

The world is currently experiencing its worst economic turbulence since the Great Depression of the 1930s on the back of $3 \mathrm{~F}$ crises (fuel, food, and financial). No region has been spared. The 2009 ADB study on "The Economics of Climate Change in Southeast Asia: A Regional Review" underlined that climate change is likely to be one of the most significant development challenges confronting Southeast Asia in the twenty-first century. The Southeast Asian GDP growth is likely to fall from $4.3 \%$ in 2008 to $0.7 \%$ in 2009, which could result in tens of millions of people, who would otherwise be lifted out of poverty, being trapped, and would make the achievement of the Millennium Development Goals (MDGs) more challenging to attain. At the same time, findings of the Emerging Asia study undertaken by the Washington-based Centennial Group shows that, in the next 20 years, $50 \%$ of world GDP will be contributed by Asian countries, and 5 of the world's top 10 economies will be based in Asia.

The above observations on climate change are corroborated by the findings by the CSR Asia study titled CSR in 10 , which examined the top $10 \mathrm{CSR}$ issues emerging in the next 10 years, and climate change emerged as the top corporate social responsibility issue, followed by corporate governance, and labor and human resources. It also notes that the way businesses impact on the environment is likely to come under much closer scrutiny. Environmental performance will increasingly be part of a company's reputation and brand. Climate change is seen as dominating the CSR agenda for the next 10 years.

S. Irandoust $(\bowtie)$

Asian Institute of Technology (AIT),

P.O. Box 4, Klong Luang,

Pathumthani 12120, Thailand

e-mail: president@ait.asia
The efforts to address climate change are also shifting from strategies for mitigation to a new emphasis on adaptation. Though there will be new thrusts on energy efficiency and promoting renewable energy sources, companies need to demonstrate that they are reducing their own carbon impacts, as well as working in partnerships with others on adapting to climate change.

There exist "win-win" measures that address climate change and there are also good sustainable development practices. This has been considered by many countries, developed and developing, that have included specific "green measures" in their proposed or announced fiscal stimulus packages. Leaders of the G20 at the 2009 London Summit agreed to make the best possible use of investment funded by fiscal stimulus programs toward the goal of building a resilient, sustainable, and green recovery, and to make the transition toward clean, innovative, resourceefficient, low-carbon technologies and infrastructure. Green development plans are already on the agenda in the People's Republic of China, Japan, and the Republic of Korea. Similarly, fiscal stimulus is being used by many countries, including Thailand, Philippines, Indonesia, and Singapore, to support domestic demand through tax cuts, investment in infrastructure, and increasing spending on social programs. There may be scope for building into such stimulus packages "green investment" programs that combine adaptation and mitigation measures with efforts to shore up the economy, create jobs, and reduce poverty. Countries could integrate adaptation and mitigation actions more closely into their sustainable development poverty reduction strategies and policy-making processes. A study by the USAID shows the possibilities for implementing clean energy solutions (Fig. 1). While the existing international funding sources available for supporting adaptation and mitigation actions in developing countries fall far 
Fig. 1 Ranking results for clean energy options that can be implemented through regional cooperation programs. The ranking provides an approximate prioritization of options that have strong regional applicability and have the greatest potential for lowcost carbon mitigation in a short-term time frame (35 years). (Source: USAID 2007). CCGT combined cycle gas turbines, $\mathrm{CHP}$ combined heat and power, $\mathrm{CO}_{2}$ carbon dioxide, $E E$ energy efficiency, $I G C C$ integrated gasification combined cycle, $P V$ photovoltaic

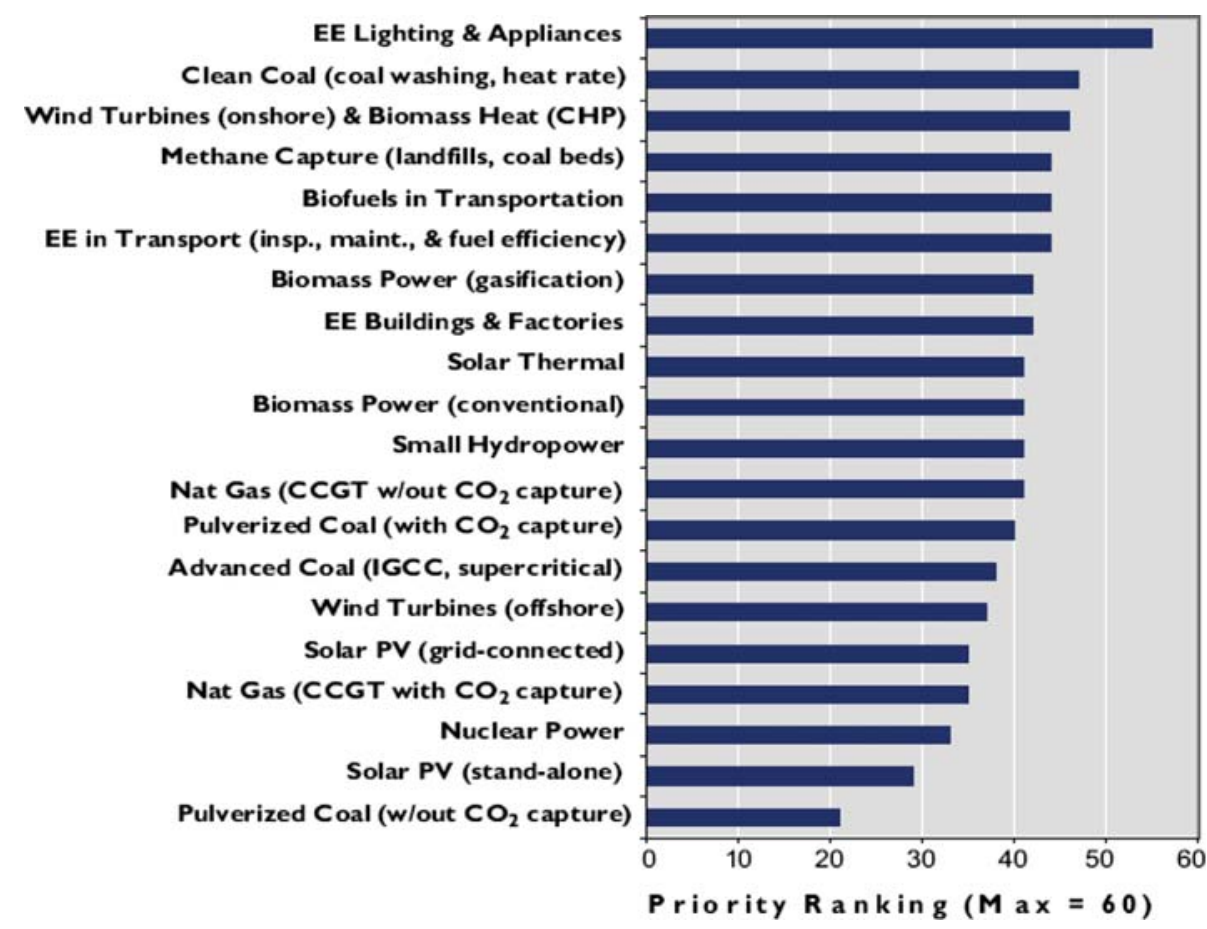

short of what is required, and need to be scaled up, the region should enhance institutional capacity to make better use of existing and potential international funding sources. Blanford et al. (2009) have presented their analysis using the design specified by the Energy Modeling Forum (EMF) Transition Scenarios study on achieving climate stabilization goals with delayed participation by developing countries. Their results indicate that a radiative forcing target equivalent to $450 \mathrm{ppm}_{\mathrm{v}} \quad \mathrm{CO}_{2}$-e cannot be met, even allowing for an overshoot of the target during the entire twenty-first century and full participation of developing countries. With delayed participation of developing countries, a target of $550 \mathrm{ppm}_{\mathrm{v}} \mathrm{CO}_{2}$-e is only attainable with pessimistic assumptions about economic growth, and even then only at very high cost. A target of $650 \mathrm{ppm}_{\mathrm{v}} \mathrm{CO}_{2}$-e can be met with delayed participation for a more affordable cost.

With such dim scenarios, the present crisis offers an opportunity to start a transition toward climate-resilient and low-carbon economies. However, to re-road the economy requires that the human resources and institutions are well equipped to address these new and unconventional challenges. Institutions of higher learning are the ideal platforms to initiate the beginnings of this change.

Higher learning institutions have an important role in sustainable development efforts, and especially in addressing emerging issues (climate change, disaster mitigation, post conflict countries, etc.) as well as creating new leaders. Key components and activities when working in a development concept must entail interaction between research and education, the practical implementation in the field, and the feedback into the academic system and the consecutive flow of information between the actors on all levels-end-users such as farmers, local authorities, governments, and academic/research institutions.

Research is not only about increasing competency within some discrete knowledge fields. It is also about cultural differences as a source of potential for creation, innovation, critical thinking, and development. The Asian Institute of Technology (AIT), which is celebrating its 50th anniversary this year, has conducted research of relevance to the region from its inception and sustainable development has been at the core of major projects carried out in various parts of Asia. Human problems today are global, and AIT, therefore has an international perspective in all its activities. The AIT's approach has always entailed partnership with national universities and governments in order to establish not only the technology dissemination, but also the thinking of development behind such technology dissemination. The overall objective has been to put in place a cycle of innovative research and application, integrated with education and training and implementation through outreach work in the field, with the aim to benefit and empower the poorer strata of the population.

Four major recent initiatives are aimed to launch the AIT in its direction of contributing toward sustainable development and climate change issues:

- First, the Institute will focus its research in the knowledge area of "Sustainable Development in the 
context of Climate Change," which is an important and key element of the "AIT Strategy 2013" document.

- Second, as a lead contributor to regional sustainable development, the AIT has been designated by the United Nations as the site of the world's first Regional Centre of Excellence on the Millennium Development Goals (MDGs), dedicated to the promotion and achievement of the MDGs in Southeast Asia through education and training. More recently, a "Joint Declaration on the Attainment of the Millennium Development Goals in ASEAN" was signed and adopted by the ASEAN leaders at the 14th ASEAN Summit officially acknowledging the Center as an important avenue and platform for the ASEAN to utilize in meeting its MDG targets.

- A “Yunus Center at AIT", named after Professor Muhammad Yunus, recipient of the 2006 Nobel Peace Prize, has been established this year to address issues of food security, social business in agriculture, applications of ICT in agriculture, and to act as a watchdog to encourage research that will have a positive impact on poor people's lives.

- Fourthly, an "Asian Center for Corporate Social Responsibility at AIT" (ACCSR) has been recently launched, which is a joint venture partnership between the AIT and CSR Asia. Its mission is to advance the development and implementation of effective sustainability solutions both for and by business, and to facilitate development of the supportive framework conditions for corporate social responsibility and sustainable development. The ACCSR will provide a platform for dialog and innovation for the representatives of the private sector in seeking creative solutions for the challenging issues of sustainable development.

The pathway to enhancing sustainable development, considering not only the three pillars of economy, environment, and society, but a cross-cutting theme, namely, the human dimension (self), is not easy. The formulation and implementation of sustainable development policies at international, national, and local levels require a new breed of:

- Policymakers and planners, who can prepare and execute sustainable development policies; and

- Technical experts working in various sectors, who can develop and disseminate environmentally and socioeconomically sustainable technologies.
During the last few years, it is becoming increasingly important for institutions of higher learning to start considering sustainable development efforts and initiatives from a significantly longer term perspective or horizon considering sustainable development in a more comprehensive manner. The ADB's long-term strategy looks at a 2020 period, while the OECD projects 2030 scenarios as to how higher education could evolve, with the aim of informing and facilitating strategic change to be made by government decision makers and other key stakeholders in higher education.

While traditionally it may have been the role of a university to take a didactic role in development, telling society what is right and what is wrong, and providing science and technology based upon research done within the ivory tower, that role is changing. Society, with its ever increasing number of knowledge centers, has begun to talk back. Therefore, higher education needs to undergo, and is undergoing, fundamental changes. More and more, universities are becoming neutral platforms on which to build collaboration between the public and private sectors and between those who conduct research and those who use it. Universities are becoming the facilitators of dialog and technology transfer.

Therefore, we need to forge forward-looking curricula that tear down the walls of traditional disciplines. Institutions of higher learning should be able to train graduates who could address these emerging issues. This is definitely a period for change.

\section{References}

AIT Strategy 2013

Asian Development Bank (ADB) (2009) The economics of climate change in Southeast Asia: a regional review. ADB, Manila

Blanford GJ, Richels RG, Rutherford TF (2009) Feasible climate targets: the roles of economic growth, coalition development and expectations. Energy Econ (accepted for publication)

CSR Asia report on the "CSR in 10" project

U.S. Agency for International Development (USAID) (2007) From ideas to action: clean energy solutions for Asia to address climate change. USAID, Bangkok 